\title{
Documento
}

\section{Grupos de Estudos Interdisciplinares do IEA}

Como já foi feito no número anterior de estudos AVANÇADOS, onde apresentamos a problemática da Biologia Molecular e sua ênfase como área de concentração do IEA, abordamos agora o tema das Ciências Ambientais. Nos próximos números, serão tratadas as outras duas áreas prioritárias de atuação do Instituto de Estudos Avançados: História das Ideologias e Mentalidades, coordenada pelos profs. Alfredo Bosi e Carlos Guilherme Mota; e a área de Economia e Politica, coordenada pelo prof. Paul Singer, que promoveu no mês de julho passado o Simpósio Internacional Democratizing Economics: discourse and praxis (Towards a New Economics), em convênio com o Woodrow Wilson International Center for Scholars, de Washington, DC.

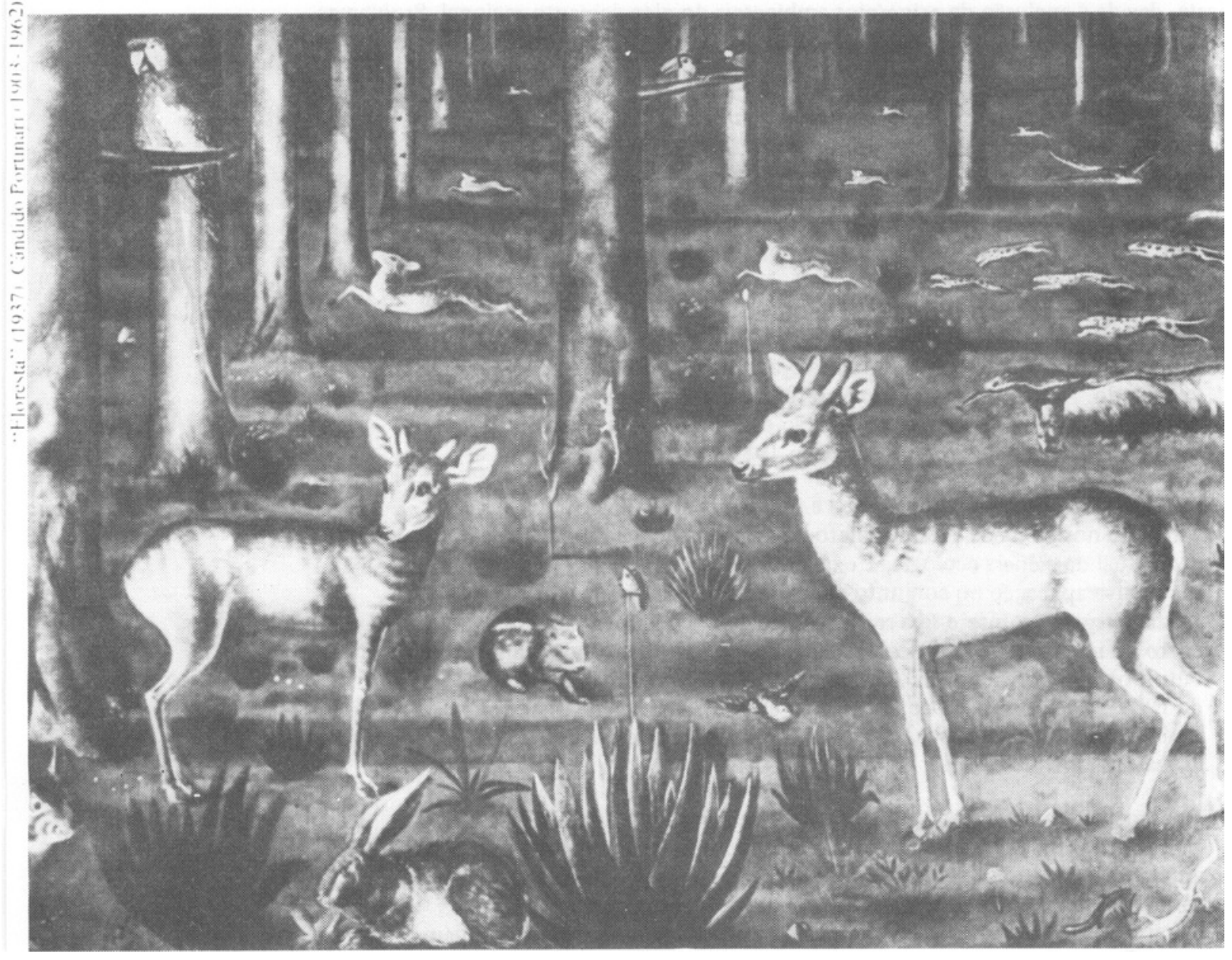




\section{CIENCIAS AMBIENTAIS NO IEA}

O Grupo de Estudos sobre Ciências Ambientais formou-se no primeiro semestre de 1987, sob a coordenação do prof. Jose Galízia Tundisi e, em 1988, suas atividades com um tratamento priorizado encontram-se em fase de implantação.

O uso eficiente de recursos naturais renováveis e næo-renováveis, e a recuperação de ecossistemas, requerem uma atuação integrada $e$ interdisciplinar que tem sido desenvolvida nos anos recentes na área de Ciências Ambientais. Este abrangente campo de atividade científica tem uma ampla interface com o planejamento do desenvolvimento econômico e social, principalmente no que se refere ao gerenciamento de recursos, à previsão e quantificação de impactos ambientais, e à analise e busca de tecnologias adequadas para controle ambiental e resolução de problemas relativos à poluição e degradação ambiental.

A inserção de conceitos ambientais e de teoria ecologica no processo de planejamento demanda uma análise crítica da situação atual do Brasil e da América Latina quanto a polfticas de desenvolvimento e o uso de recursos, poluição, crescimento sustentado com gerenciamento ambiental e prognósticos com vários cenários alternativos. A busca de modelos alternativos e de seus possíveis impactos nos sistemas naturais é um ponto importante de atuação na área de Cièncias Ambientais. Ela envolve a análise e introdução de ampla conceituação teórica, a qual deve ser incorporada ao processo de planejamento a longo prazo.

A crítica situação em muitas regiōes do Brasil, com relação ao ambiente, é, em grande parte, devida à exclusão de princípios ambientais do planejamento regional. Problemas como energia e ambiente, a situação ambiental das grandes metrópoles, a expansão da fronteira agrícola demandam uma profunda análise e a proposição de soluções criativas adequadas à realidade regional.

Um outro aspecto importante é a formação de recursos humanos em Ciências Ambientais.

Tendo em vista esta problematica, o Instituto de Estudos Avançados da USP, na sua área de concentração em Ciências Ambientais, deverá desenvolver atividades em três projetos principais:

1) Ańlise crítica do processo de desenvolvimento e suas repercussões ambientais; bases ambientais e alternativas para o desenvolvimento regional sustentado. Neste projeto, o primeiro tópico a ser tratado desenvolvera o tema Energia e Ambiente, com a criação de um grupo de trabalho sobre este tema e a realização de um seminario em 1989 (primeiro semestre);

2) Análise do desenvolvimento teórico e a situação atual da ecologia e sua aplicação nos trópicos. Neste projeto, procurar-se-á aprofundar a análise conceitual da ciência ecológica e examinar alternativas e mecanismos para sua efetiva aplicação no conjunto de processos e ecossistemas tropicais. Nesta perspectiva, insere-se a realização de dois seminários, um em 1988 e outro no inicio de 1989: "Ecologia, Teoria e Práxis" (segunda quinzena de outubro), e "Modelagem Ecológica: teoria e aplicações" (9-13 de janeiro de 1989), este último em conjunto com a Escola de Engenharia de São Carlos (Centro de Recursos Hídricos e Ecologia Aplicada e Centro de Processamento de Dados);

3) Atualmente, existe uma enorme atividade relacionada à analise de impacto ambiental. Bases seguras para uma analise de impacto ambiental provêm da implantação de metodologias adequadas com extensa conceituação teórica e conhecimento cientifico de processos ecológicos, organização espacial e hierarquias de fatores associadas a aspectos econômicos e sociais. Também a quantificação das analises e fundamental. Portanto, esta terceira atividade 
deverá ser desenvolvida através da criação de um outro grupo de trabalho:

Metodologias de impacto ambiental: uma análise crítica.

Os grupos de trabalho atuarão sob a forma de reuniôes, seminarios e a realização de simpósios que procurarão sintetizar idéias discutidas e produzir textos e livros.

Especialistas de outros países deverão participar desses grupos de trabalho e dos simpósios, e na produção de bibliografia original. Dentre estas, destaca-se a visita do prof. Ramon Margalef, por três meses, ainda em 1988.

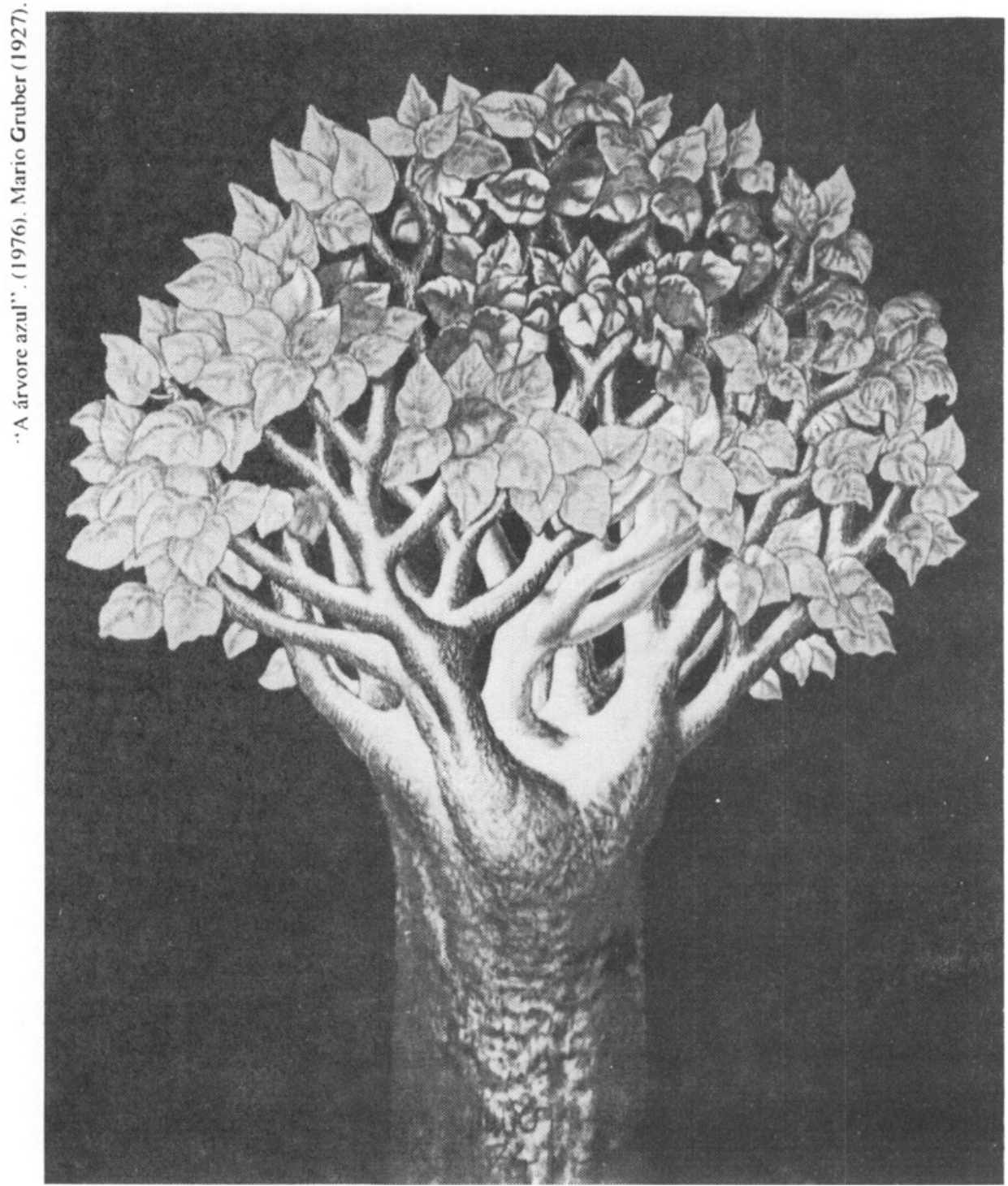

